\title{
Are there excess Sharons in genitourinary clinics?
}

\author{
Elizabeth Foley, Fred Willmott, David Rowen, Raj Patel, J L Low
}

Most doctors believe that they can determine the age and social class of a patient merely from hearing their name-but this has not been proved. In the 1990s, paediatricians seldom encounter Hildas or Ethels, and Kylies and Bradleys are yet to call on the services of elderly medicine. Stereotypes abound, but is it true that Camillas are more likely to have private medical insurance than Paulines? Above all, are those "Essex girls" Tracey, Sandra, and Sharon really women of easy virtue? With this in mind we set out to establish whether these names are overrepresented among attenders in departments of genitourinary medicine.

\section{Method and results}

We analysed the database for women in the 16-24 age group attending as patients at our department between April 1998 and March 1999. The 10 girls' names most commonly encountered were recorded and compared with data from the Office of Population Censuses and Surveys, which published a database of popular names at intervals of 10 years. ${ }^{1}$ The age of our study population spanned two data sets (1974 and 1984). The frequency of the 10 most popular names in our records was broadly similar in both official databases, so we used 1974 for comparison as it most closely approximated to the mean ages of the named groups in the study population. As Tracey, Sandra, and Sharon did not feature in the 10 most common names in our clinic, additional data were collected for these names. Data were analysed with spss version 9.0.1, using an exact one sample $\chi^{2}$ test.

In the study period 1462 women aged 16-24 attended our department. The ranking and frequency of girls' names and the mean age of these patients in genitourinary medicine clinics and their frequency in the population for that age group are shown in the table.

Girls' names most frequently encountered in a Southampton genitourinary medicine clinic

\begin{tabular}{llcccc}
$\begin{array}{l}\text { Rank in } \\
\text { clinic }\end{array}$ & Name & $\begin{array}{c}\text { Mean age } \\
\text { (years) }\end{array}$ & $\begin{array}{c}\text { Total (\% of } \\
\text { all patients) }\end{array}$ & $\begin{array}{c}\text { National } \\
\text { rank }^{*}\end{array}$ & $\begin{array}{c}\% \text { of birth } \\
\text { cohort }^{*}\end{array}$ \\
\hline 1 & Sarah & 21.7 & $55(3.8)$ & 1 & 3.8 \\
\hline 2 & Emma & 20.2 & $35(2.4)$ & 4 & 2.3 \\
\hline 3 & Kelly & 20.9 & $34(2.3)$ & 47 & 0.4 \\
\hline 4 & Louise & 19.6 & $30(2.0)$ & 13 & 1.4 \\
\hline 5 & Claire & 21.5 & $27(1.8)$ & 2 & 2.8 \\
\hline 6 & Lisa & 21.3 & $26(1.8)$ & 5 & 2.2 \\
\hline 7 & Rachel & 21.7 & $23(1.6)$ & 12 & 1.4 \\
\hline 9 & Clare & 22.0 & $22(1.5)$ & 15 & 1.1 \\
\hline 10 & Michelle & 21.1 & $17(1.2)$ & 7 & 1.8 \\
\hline 30 & Nicola & 21.4 & $16(1.1)$ & 3 & 2.6 \\
\hline 35 & Sharon & 22.4 & $7(0.48)$ & 17 & 1.0 \\
\hline 62 & Tracey & 22.8 & $5(0.34)$ & 26 & 0.78 \\
\hline
\end{tabular}

*Data from Office of Population Censuses and Surveys, 1974 database.

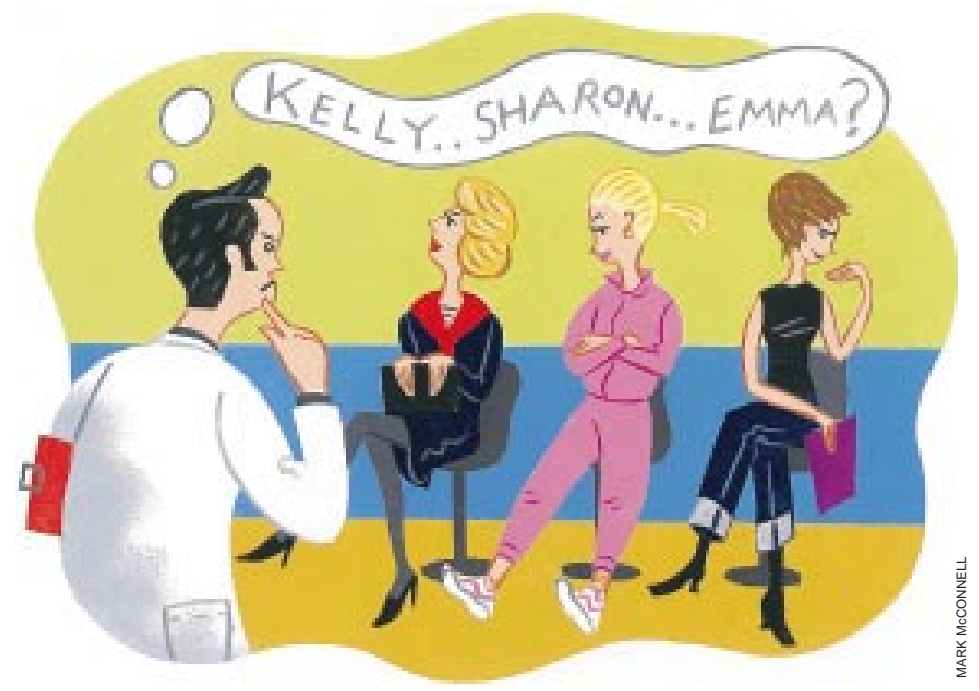

\section{Comment}

Most of the top 10 names for women attending our department were seen with the frequency expected by the incidence of the name in the population. The names most often encountered were Sarah (3.8\%) and Emma (2.4\%).

The much maligned Sharon, Tracey, and Sandra were seen half as often as expected $(\mathrm{P}=0.003)$, and as we enter the new millennium, these names make way for the more popular "Hampshire girls" Kelly and Louise $(\mathrm{P}<0.0001$ and $\mathrm{P}=0.035$ respectively).

Having detected a significant difference in the names of women attending our genitourinary medicine clinic in a retrospective study, we suggest that a prospective randomised study on an "intention to name" basis should be performed. This may, however, have recruitment difficulties.

Contributors: EF initiated the research, interpreted the data, wrote the paper, and is the study guarantor. FW participated in data collection and commented on the draft. DR participated in discussion of the paper. RP had the idea for the study and participated in research methodology and discussion of the paper.

JLL did the statistical analysis.

Funding: None.

Competing interests: None declared.

1 Merry E. First names: the definitive guide to popular names in England and Wales 1944-1994. London: HMSO, 1995.

\section{Endpiece}

On ageing: fading memory

Thus aged men, full loth and slow,

The vanities of life forgo,

And count their youthful follies o'er,

Till Memory lends her light no more.

Rokeby, Sir Walter Scott (1771-1832)

Submitted by Fred Charatan, retired geriatric psychiatrist, Florida
Department of Genitourinary Medicine, Royal South Hants Hospital, Southampton SO14 OYG Elizabeth Foley specialist registrar Fred Willmott consultant David Rowen consultant Raj Patel consultant Department of Medical Statistics and Computing, Southampton General Hospital, Southampton SO16 6YD

J L Low statistician Correspondence to: E Foley

BMJ 1999;319:1615 